\title{
ALGUMAS CONSIDERAÇOESS DE ENFERMAGEM SOBRE AS NECESSIDADES PSICO-SOCIAIS E PSICO-ESPIRITUAIS DOS PACIENTES
}

* Lygia Paim

\begin{tabular}{l|c|}
\cline { 2 - 2 } & RBEn/03 \\
\hline
\end{tabular}

PAIM, L. - Algumas consideraçōes de enfermagem sobre as necessidades psicosociais e psiooespirituais dos pacientes. Rev. Bras. Enf.; DF, 32 : 160-166, 1979.

\section{INTRODUÇĀO}

Este assunto parece-nos um dos mais oportunos não somente pela agudeza do empenho com que vem sendo proposto pelos enfermeiros, mas principalmente porque vale, por si só, como um libelo contra as situações que configuram o campo próprio da assistência. à saúde e, ainda por esta mesma razão, porque corresponde à necessidade premente de se levantar uma tese em favor da humanização das Instituições de Saúde existentes em nosso país, cujos padrōes de atendimento já não satisfazem mais as necessidades e as demandas da sociedade de nosso tempo.

$A$ vista de tratar-se apenas de um artigo, compete-nos esclarecer, desde já, e antes mesmo que possamos nos permitir uma postura mais objetiva diante da problemática que envolve as necessidades psico-sociais e psico-espirituais do paciente, que não é nosso intento trazer à luz da discussão, nem a essencialidade das formulações mágicas nem a propositalidade de métodos especificamente pragmáticos que, prontamente, poderiam nos conduzir às soluções imediatas, mas, tão somente, mobilizar a atenção dos leitores para certos aspectos da questão, os quais, de resto, garantem à mesma, a relevância necessária para a validez científica.

Um deles, ao nosso ver, define a própria atitude profissional tal como deve ser entendida face às necessidades psicosociais e psico-espirituais do paciente, enquanto que o outro, caracteriza a conduta profissional apropriada ao atendimento dessas mesmas necessidades. Cabe esclarecer ainda que, estes dois aspectos não esgotam, de modo algum, o estudo da questão, e nem mes-

* Livre-Docente pela UFRJ - Assessor do Grupo setorial de Saúde da Secretaria de Fnsino Superior - SESU|MEC.

- Artigo adaptadn de apresentaçāo de tema oficial næ్o publicado CBEn 1974. 
PAIM, L. - Algumas consideraçōes de enfermagem sobre as necessiclades psicosociais e psicjespirituais dos pacientes. Rev. Bras. Enf.; DF, 32 : 160-166, 1979.

mo chegam a minimizar as preocupações supostamente contidas na dimensāo psicológica da consciência profissional que se encontra inquestionave!mente dicotomizada nos termos da educação e da prestaçāo de serviços para a proteção da saúde.

- Considerações sobre o homem, tal como indicam os principios que orientam uma filosofia de Enfermagem

O homem inteiro vive, e só assim poderá viver. Repartido, sectorizado, morrerá por certo, ou procederá como morto. Peças de seu sistema interdependente fazem parte de uma só engrenagem, esta que lhe aciona para a vida em proveito do amor e da criatividade. Fazendo ciência biológica o homem assegura a continuidade da espécie; entregando-se aos experimentos tecnológicos, terá garantido o homem seu alvo e o material necessário às lutas que lhe esvaziam as agressōes. E, nesta troca compensatória, emocionalmente defensiva, o homem de hoje se compraz num estilo de vida, tão dificilmente entendido, principalmente, quando olhado apenas através do antagonismo de suas próprias predileçōes. Por isso mesmo, será necessário buscá-lo na intimidade de suas próprias experiências para compreendê-lo no cume de suas determinantes, e mais essencialmente ainda, para aceitá-lo na conseqüencia que lhe laz homem, dotado ou não de possibilidades para viver às expensas de sua própria razāo. Mas, para tanto é preciso compreender que psicológica e espiritualmente o homem nāo vive apenas no presente, pois seu tempo depende da importância do acontecimento, e que é o significado da experiência o que conta para suas esperanças, ansiedades e progresso, como pessoa. $O$ homem tem assim, deste modo, uma relação flexivel e criativa com o espaço e o tempo, uma relação na qual o principio orientador é o significado qualitativo de suas experiências pessoais, estas que estarão sempre em razão de suas relaçōes com o outro, com aquele que se antepõe ao seu lugar, com aquele que com ele priva da vida nos grupos, ou ainda com aquele que a ele se intercepta, para uma ação de que-rela despertando-lhe um sentimento incomparável de vitória ou a consciência mórbida de um desvalor.

Assim é que, de modo geral, chegam os homens às instituiçōes de saúde - enfermos totais, embora ingenuamente cuidem de atentar para uma causa isolada, essa que possa ser a apontada como responsável exclusiva pela falência em qualquer setor que corresponda à organização estrutural de seu sistema completo. E, no entanto, o amor quase sempre o aspecto mais relevante do problema. Amor suporte, amor segurança, amor significativamente dimensionado em todas as facetas da condiçāo humana, olhado eomo potencializador das energias vitais que estāo no domínio físiológico dos organismos vivos, a florescer livremente. Assim disposto, qualquer problema relativo às necessidades psico-sociais $\mathrm{e}$ psico-espirituais poderia ter a mais alviçareira das soluções ou até mesmo, quem sabe, nem chegar a assumir certa estatura. Toda dificuldade a lhe caracterizar como problema, estaria a residir na impropriedade das decisões de ajuda, oferecidas por aqueles que nāo estão devidamente acordes com as sutis implicaçōes de seus papéis profissionais. Ajudar, quando se trata da área afetiva, é uma difícil arte de ser útil e hábil sem, contudo, onerar as emoções do receptor ou iniciá-lo no ofício de pedinte fácil. Mesmo porque, aquele que melhor pode ajudar, em hipótese alguma, deve dispensar a oportunidade de educar através do reconhecimento das condições potenciais daquele que é o ajuda- 
PAIM, L. - Algumas consideraçōes de enfermagem sobre as necessidades psicosociais e psicoespirituais dos pacientes. Rev. Bras. Enf.; DF, 32 : 160-166, 1979.

do - e, neste caso, bastará uma garantia de apoio, contida na habilidade de trabalhar com certas ansiedades deslocadas - , permitindo com segurança as expressões de sofrimento e tensão a que muitos individuos têm que se entregar, antes mesmo que se disponham a efetuar qualquer tentativa de reformulação emocional ou atitudinal.

Sem conhecimento de causa, sem preparo ou atenção para os perigos de envolvimento ou identificação emocional, não será possivel dar suporte ou fiança às necessidades psico-sociais e psico-espirituais a quem quer que seja. De modo algum, entretanto, queremos assegurar aqui a crença de que somente uma enfermeira "especialista" pode lidar adequadamente com as ansiedades oriundas das necessidades emocionais, sociais e espirituais do paciente. Ao contrário, as preocupações com o homem como um todo, difusas em todos os aspectos relativos ao cuidado do paciente, devem sobrepor-se àquela visão fragmentada que retalhava o homem em setores geométricos, deixando-o, tantas vezes a padecer por mera imprevisão do hierarquizador dessas diversas áreas de atenção.

Convém esclarecer, pois, que, em nossa opinião, a garantia do sucesso de qualquer intervenção humana depende, em última instância, da maneira pela qual são atendidas as demandas emocionais, mesmo porque o teor de emoções pode servir como crivo através do qual será possivel avaliar melhor a condição ou a situação especifica em que se encontra envolvido o paciente. Sem dúvida alguma, o resultado a que se deseja chegar, em termos de expectativas ou de proposições de ajuda, se assentará no modo pelo qual se processa a conduta profissional desse atendimento. Neste sentido, ouvir com atenção, se- ria a conduta primária a ser utilizada pela enfermeira no contato diário com o paciente.

A justo título, secundando a opinião de Upjely (1) diriamos que quando ouvimos o paciente, pelo menos três objetivos podem ser alcançados:

a) conhecer o principal tema de suas preocupações;

b) interpretar o seu tipo de humor durante a narrativa (ou seja, a avaliação da importância que ele atribui a seu próprio problema); e

c) difinir a qualidade da interação estabelecida (o que ele chega a confidenciar à enfermeira e o que comunica em termos de expectativas pessoais).

E, apenas para enfatizar, gostariamos de afirmar que, na maioria das vezes, ao ouvir o paciente nada é mais necessário do que uma atenção silenciosa; bastará isto, muitas vezes, para assegurar-lhe que tomamos conhecimento de suas preocupações e que as mesmas serão levadas em conta, no devido tempo, à medida que caracterizamos, em termos de relacionamento com ele, a nossa própria conduta profissional. Não nos deverá preocupar, entretanto, as respostas imediatas, mesmo porque certos problemas quando resolvidos à custa de decisões prematuras, quase sempre suscitam outros problemas de natureza, por vezes, mais complexa, o que fatalmente dificultará, ainda mais, a avaliação adequada da situação total do paciente.

Por esta razão, é que acreditamos que todo indivíduo que se atenha ao cuidado com a vida humana jamais poderá se apresentar desprovido do preparo adequado de condições apropriadas que the permitam assumir a responsabilidade de intervir, com propriedade,

(1) Gertrud Upjely. 
PAIM, L. - Algumas consideraçōes de enfermagem sobre as necessidades psicosociais e psiçespirituais dos pacientes. Rev. Bras. Enf.; DF, $32: 160-166,1979$.

em todas as questōes concernentes à dicotomia corpo-alma, tal como entendida nos termos de um sistema altamente diferenciado, no qual condição propicia condição, e o sentimento de satisfação é o resultado da atenção global às necessidades que caracterizam o homem.

Estas primeiras consideraçōes situam a nossa posição diante do tema, porquanto acreditamos que a maneira pela qual a enfermeira conduz o atendimento das necessidades psico-sociais e psico-espirituais do paciente deve caracterizar a atitude face à propositalidade dos objetivos profissionais da enfermagem. E é esta atitude que, a nosso ver, definida no pleno conhecimento das influências comportamentais e no dominio da dinâmica das relações interpessoais, indubitavelmente, se ajuntada aos excelentes recursos dos procedimentos técnicos, deve explicitar a objetividade científica da enfermagem, conferindo, desta forma, firmeza ao status profissional da enfermeira no campo próprio das ciências da saúde.

- Um enfoque da prática profissional do enfermeiro

Em verdade, na nossa opinião, os homens vivem, convivem, pressentem e sentem, por si sós, quais são as suas autênticas necessidades e as dos outros, independentemente da adoção de qualquer classificação prévia relacionada com as necessidades humanas. $\mathbf{E}$ é por este motivo, que achamos que a validez da resolução de um problema pertinente ao tema em questão, não depende propriamente ou tão somente do conhecimento que se possa ter de quaisquer listagens das necessidades humanas, tal como encontradas nos livros textos que habitualmente consultamos. O que nos deve preocupar é a busca de uma atitude coerente com a responsabilidade que deve ser assumida frente às mais diversas manifestaçōes do paciente, e que possa equivaler, em qualquer situação, à conduta profissional exigida e sistematicamente orientada para a identificação e $o$ atendimento das necessidades subjacentes aos mals diferenciados tipos de reaçōes individuais, necessidades que são singulares a cada pessoa em determinada situação.

Sucede contudo, que, embora parecendo por demais complexo para muitos de nós, este tema é em si mesmo, pleno de significações exatamente porque faz parte do dia-a-dia, do quotidiano de qualquer enfermeira. Por isso mesmo, achamos que o assunto não se constitui absolutamente numa "novidade", mas sabemos também que o mesmo não tem recebido a valorização devida no que tange aos tratamentos de enfermagem. $\mathbf{E}$ isto é, talvez, porque tenhamos deixado de conferir à questão o destaque que ela merece no âmbito das atividades profissionais; na realidade, o que testemunhamos, fre.qüentemente, é a crescente valorização das necessidades que se referem à sobrevivência, em detrimento de um maior interesse pelos problemas pertinentes às necessidades psico-sociais e psicoespirituais do paciente, estas que lhe assegurarão significado maior para a vida, enquanto pessoas humanas.

Se admitirmos, entretanto, que a conduta de enfermagem deve sublinhar, em primeiro plano, uma abordagem centrada no paciente como pessoa e que isto implicará, necessariamente, na compreensão do homem como um todo, certamente teremos de nos haver com sérias implicações, todas elas relativas ao cuidado total do paciente, o que significará que, não obstante possam representar graves desafios, nem por isso escapam ao âmbito de nossas possibilidades presentes.

Entretanto, pelo que diz respeito à prática profissional, o que temos observado é que continua ocorrendo, e até 
PAIM, L. - Algumas considerações de enfermagem sobre as necessidades psicosociais $\mathbf{e}$ psicoespirituais dos pacientes. Rev. Bras. Enf.; DF, 32 : 160-166, 1979.

com bastante freqüência, a nosso ver, uma certa omissão quanto às responsabilidades diagnósticas da enfermeira com relação às necessidades psicosociais e psico-espirituais do paciente.

Ora, se aceitarmos, do ponto de vista de uma visão sistêmica, que a omissão no atendimento de enfermagem, em qualquer área das necessidades humanas, pode representar a falência mesma daquilo que entendemos por cuidado global do paciente, e que este fato, por si só, costuma ser interpretado como negligência, sem dúvida alguma. contrariamos com isso, tanto os ditames dos Códigos de tetica Profissional, como também os imperativos categóricos da Consciência Moral. Nesse caso, não poderemos deixar de reconhecer que, como contribuintes ao progresso social e científico da enfermagem, somos obrigados a envidar todos os esforços e a mobilizar todos os recursos para resolver quaisquer dificuldades relativas às necessidades psico-sociais $e$ psico-espirituais do paciente, tanto quanto até então se conhece e são tratadas as necessidades psico-biológicas.

Sabemos que, como enfermeiros, somos os participantes da equipe de saúde que dispõem da vantagem de poder verificar, de modo mais continuo, os vários aspectos da situação do paciente, e que se é essa mesma vantagem que nos garante a posição mais estratégica para decidir acerca dos "porquês", dos "como" e dos "quando" relacionados rom os problemas de enfermagem. Então, diante desse fato, não poderemos mesmo deixar de utilizar a oportunidade para antecipar, em termos de causas e conseqüências, a natureza e extensão desses problemas, a fim de que possamos intervir, com a liberdade que nos é garantida pelas prerrogativas da posição, em todas as circunstâncias situacionais que possam afetar, de modo negativo, a integridade bio-psico-social do paciente.
Ainda neste sentido, vale acrescentar que temos que admitir a enfermagem como força que advém da própria sensibilidade da enfermeira para captar a relevância das condições que existem à sua volta e para interpretar o significado real do mundo que compreende as respostas do paciente. Por isso mesmo, a enfermagem deve ser, consequientemente, entendida como força que se orienta no sentido das mudanças desejáveis, agindo sobre tudo aquilo que possa interferir negativamente na sistemática processual que fundamenta a conduta profissional da enfermeira face à dimensão psicológica que comporta o cuidado total do paciente.

Ousamos sugerir que algumas dessas mudanças estão ligadas diretamente à prática profissional e devem favorecer a reorganização dos esquemas de trabalho que, na grande maioria das Instituições de Saúde, continuam estaticamente dirigidos para o estudo e o cuidado ligado apenas a entidades clinicas e voltado para o cumprimento de normas e execução de procedimentos técnicos relacionados com certos aspectos do cuidado do paciente, sem nenhuma preocupação de entendê-lo como pessoa-centro de interesse e de atenção de todos os integrantes da equipe de saúde. Isto, a nosso ver, será a mudança maior a ser provocada nos enfermeiros, aquela que determinará todas as facilidades para as demais mudanças. E nenhuma área de necessidades humanas no paciente será a partir dai, menos atendida que outra. Assim é que, as omissões em certos aspectos do caidado do paciente até então surgidas, tenderão a desaparecer, porque os dados que serão identificados, analisados e tratados, delinearão um perfil do homem como um todo, unificado, e então estarão valorizados, entre outros, os dados que compōem o perfll psicosocial do paciente. Somente a partir desse momento, 0 atendimento mals 
PAIM, L. - Algumas consideraçóes de enfermagem sobre as necessidades psicosociais e psicoespirituais dos pacientes. Rev. Bras. Enf.; DF, 32 : 160-166, 1979.

amplo das necessidades do paciente se dará, e desse modo, a atenção estará voltada para as expectativas dele mesmo, ao invés de continuarmos encimando-lhe as nossas.

Outras mudanças, contudo, serão, a nosso ver, forçosas em termos de preparo profissional, para que o enfermeiro possa ter um desempenho correspondente às demandas sociais e profissionais de sua época. Assim é que uma revisão curricular impōe-se a fím de que se considere a necessidade de dar igual ênfase às Ciências Sociais e Humanisticas e às Ciências Físicas e Biológicas, ao lado de uma abordagem orientada para uma Assistência de Enfermagem a partir da expectativa da Comunidade. No que tange a conceitos e habilidades, sem dúvida alguma, os de Enfermagem em "Saúde Pública" e os de "Enfermagem Psiquiátrica" precisam ter exploração mais adequada, em termos de abrangência social.

Quanto ao método, deveremos buscar, por excelência, o de Resoluçāo de Problemas, calcado em situaões de indivíduos que, eventualmente, têm que assumir o papel de pacientes. Uma das medidas paralelas a todas até aqui já mencionadas, e das mais importantes para o êxito da identificação e tratamento dos problemas psico-sociais dos pacientes, será aquela que venha a favorecer um idêntico tratamento também àqueles que se desvelam em atender, e que nem sempre, encontram-se em condições internas para tão arrojado mister.

Isto requer, sem dúvida, um estudo dos problemas humanos da própria equipe de saúde, numa visão administrativa, enfaticamente preventiva, de vez que, minguadas ofertas advirāo sempre das exiguas reservas, o que faz limitar bastante as expectativas do outro, ao tempo em que desvanece o interesse geral. Precisamos aprender a avaliar a existência dos potenciais afetivos assim como as disponibilidades que demarcarāo a extensa promessa que assumimos ao servir a outrem. Isto nos trará segurança e reafirmará a nossa indispensável auto-estima, enquanto pessoas e enquanto grupo profissional.

Mais uma outra medida cabe apresentar. E esta como ainda mais valiosa: a de que, à toda a equipe de saúde fosse dado conhecer e utilizar todos os recursos disponiveis na Comunidade, aqueles pertinentes à área específica da problemática existente, envolvendo especialistas e generalistas diversos, capazes de, unidos, reforçarem-se para uma ação bem mais efetiva, àquela que, pela própria estrutura extrapolasse as possibilidades da enfermagem em si mesma.

Esta última preocupação, prende-se às possibllidades de alguns desacertos bem passveis de ocorrência, quando aos enfermeiros, por qualquer circunstância, vierem faltar experiência ou habilidade para um adequado manuseio das ansledades demandadas do próprio exercício de viver.

Quanto a princípios, nenhum seria mais útil ao grupo de enfermeiros que o principio de ação coletiva ao invés de tomar como fundamental a açāo individual e isolada.

Servir é um dever que envolve sempre enormes responsabilidades; porque servir bem, é mais que um dever: é arte. Uma arte plena de implicaçōes tão sutis que necessariamente escaparāo ao registro humano, não só pelo que se configura como imperceptível mas, sobretudo pelas defesas que somos obrigados a recorrer quando reafirmamos a identificação das nossas necessidades de ser também atendidos enquanto servirmos ao outro. Assim não fosse, bem mais fácil e eficiente seria o árduo trabalho de ajudar a curar, este que tanto dificultamos por utilizá-lo sempre no disfarce das nossas tensōes, atingindo proporções exageradamente possessivas, 
PAIM, L. - Algumas considerações de enfermagem sobre as necessidades psicosociais e psiojespirituais dos pacientes. Rev. Bras. Enf.; DF, $32: 160-166,1979$.

aquelas que nos asseguram direitos por nós assumidos de extrema autoridade com a propriedade que não nos compete.

- Que propostas devem ser colocadas à discussão?

- O trabalho a que se deve propor a enfermeira é um trabalho essencialmente preventivo, orientado para a afirmativa de que a resposta terapêutica é sempre aquela que o paciente encontra às suas próprias custas, sem a antecipação de uma solução ansiosa a que se obrigam as necessidades pessoais dos que lhe prestam cuidados.

- A Instituição de Saúde deve ser um lugar alegre que vá além de seus muros, onde as cantigas embalem as efemérides de todos os dias - a saúde reconquistada, a paz restaurada, para novas investidas no terreno das ambiçōes humanas.
Somos parte nesta responsabilidade inadiável. Humanizemos as nossas ins.tituiçōes de saúde porque assim estaremos assegurando às mesmas, uma caracteristica essencial aos seus reais objetivos - os de valorizar o homem enquanto ser social para a sua mais plena realização.

Tais propostas em discussão não podem deixar de referir como fundamental, o compromisso social que tem o enfermeiro, e o seu engajamento no contexto do estilo de vida da população. As preocupaçōes essenciais de nossu grupo profissional terão que estar centradas além de nós, nos desafios presentes por um melhor viver das Comunidades, e sobretudo por um posicionamento declarado sobre qual a contribuição dos enfermeiros na política de saúde, e que alternativas de solução aos problemas de saúde da população são as mais convenientes para uma definição do papel da enfermagem em nosso País.

\section{BIBLIOGRAFIA}

1. BROWN, E. L. - Nuevas dimensiones en el cuidado de los pacientes - La Prensa Medica Mexicana - México - 1971.

2. GELAIN, I. - Necessidade psico-espiritual do paciente. R. Bras. Enf. 27(3): 280-289, jul. a set. 1974.

3. HAYES, J. W. e GASAWAY, R. - Human Relations in Nursing - W. B. Saunders Company - Philadelphia - London - 1961.

4. JACOBY, R. - Amnésia Social - Trad. de Sônia Sales Gomes - Zahar Editores - R. Janeiro - 1977.

5. LAING, D. R. - El cuestionamiento de la familia - Editorial Paidos - Argentina - 1971 .
6. MEGARGEE, I. E. e HOKANSON, E. J. - A dinâmica da agressāo. Trad. de Dante Moreira Leite - E.P.U. Sāo Paulo - 1976.

7. ORLANDO, J. I. - O relacion'amento dinâmico enfermeiro-paciente Trad. de Alina Maria de Almeida Souza e Maria Josephina Leuba Salum - E.P.U. - Sāo Paulo - $197 \varepsilon$

8. PAIM, L. - Quantitativos e qualitativos do cuidado de enfermagem - Tese de Livre-Docência na UF'RJ - 1977

9. PEREIRA, E. - Dignidade da pessoa humana. Logo 2(3):4-5, Maio, 1975.

10. SCHOCHET, B. R. - The difficult patient in the general hospital. Am. Fam. Physician 7:95-99, mar., 197 ? 